ARTICLE HISTORY: Received: July 10, 2021 Accepted: September 15, 2021 Published: September 19, 2021

\title{
THE ARMY, SUPERFLUOUS ACTIVITY FROM \\ THE POINT OF VIEW OF ANTHROPOECOLOGY, THAT COULD BE MADE SUSTAINABLE.
}

\author{
Leonel Chacon Anchondo \\ Industrial Engineer, Technological Institute Cd. Juárez \\ Cd. Cuauhtémoc, Chihuahua, Mexico, Calle Tepeyac \# 4030, 31520
}

\begin{abstract}
To achieve sustainability, superfluous and negative economic activities must be made productive and positive. From the point of view of Anthropoecology, the army belongs to the superfluous economically active population and the purpose is to make it more sustainable; as well as the common criminals who can be classified in the negative workforce, directing them to a positive activity.

Vast majority of soldiers receive training to operate their weapons, maintain great discipline and physical condition. The complex equipment that is currently used (2021 AD.), It is a minority who receive high-level technical instructions for normal army operations, perhaps that training allows them to work in any company or carry out some productive activity for themselves. There is the option of training privates that would like it, in a productive occupation of their choice, before finishing their service in the army, so they don't leave empty-handed and not just like another retiree.

Keywords: sustainability, productive and positive, superfluous and negative economic activities, army, criminal, training, discipline, physical condition, trade, retiree.
\end{abstract}

\section{CONTENTS}

Empires usually train their soldiers to kill the "enemy" and sometimes those "enemies" are called terrorists, to justify "something". Without going further in the development of the soldier as a human being.

Poverty is not one of the main causes of crime. Although the following example is a very small sample, it shows that a high degree of coexistence and CIVISM can be achieved, despite the economic shortcomings of any social group. From the point of view of Anthropoecology, crime occurs because the individual and society became mentally ill.

DEFINITION OF ANTHROPOECOLOGY

Anthropoecology. It is the dynamic balance in the animal, intellectual, social, cultural, spiritual, moral, ethical, economic and political aspects of the human being in conjunction with the environment in which he lives.

\section{DEFINITION OF MENTAL ILLNESS}

Definition of mental illness from the point of view of Anthropoecology.

Mental illness: It is the generation of ideas and attitudes to think, decide and act, in a physiologically healthy brain, of the human being, whose thoughts position it above other human beings, inflicting damage in most cases and obtaining profit for itself.

Ubuntu, a philosophy of life, shows that poverty is NOT a factor of dishonesty or corruption to live in peace.

"Ubuntu is an old African word that in the Zulu and Xhosa culture means 'I am because we are'. It is a philosophy of life, which consists in believing that by cooperating, harmony is achieved since happiness of all is achieved. Ubuntu sees Humanity as a whole and is at the opposite extreme of the philosophy of individualism. It appeals to solidarity and cooperation of the group and, in this sense, fits perfectly with the way of proceeding of many African peoples, in which individuals rely on each other to survive in normally hostile environments." [https://www.newsmadretierra. com/ubuntu-una-filosofia-de-vida/].

Currently it is proclaimed that countries (especially the rich ones) have and develop their armies to defend themselves or to "maintain the peace in a free world".

That is demagoguery and perennial rhetoric, since in reality they use them to attack the weaker countries; Obviously, it is said that the armies were born out of the "need" to defend the group from the attack of other groups or countries. Here is the question. What are the reasons why one group attacks another? Could it be that the leaders became mentally ill?

Looking at the history of some European kingdoms, it shows the greed of the nobles of a region, who want the reign of their own region, it shows the conflicts within the families of the same reign, to take power at any cost. ["The kingmaker's daughter",

Phillipa Gregory, (Posted by Simon \& Schuster, 2012)].

At what point did GREED take over the minds of its leaders, making them mentally ill?

Historically, armies have been to maintain the supremacy of power, they have been the promoters of technological advance, reaching levels that have invaded the privacy of the human being. Adducing to the people that technological advance is the best thing that could happen to human beings; However, it has also shown the worst of the same human being, through the invasions, destruction and massacres made by the armies, until today 2021 AD. 
It requires new mentalities and leaderships, which initially make their armies a group of patriots willing to defend their country, instead of a group of hired mercenaries who are willing to do anything for the money they make, who are on purpose, mentally ill of emboldening, replacing patriotism.

The first premise of the armies is obedience, starting from this, you create and have a group of disciplined people, who can achieve much more than retire with a pension and in some cases with severe trauma that prevents them from living in society. This obedience should be brought to daily life in social behavior, through civility.

It shouldn't be like that; but, the decomposition of society, the corruption of politicians and companies, the media, which do not contribute to building a healthy and balanced society, morally and economically, originating a disoriented, discouraged and undisciplined youth.

It may seem utopian but the army could be a positive filter for these disoriented young people, recruiting and training them in a trade, as positive for them as for society.

It is common for low-income youth to voluntarily enlist in the army, many of them, as is used say, good boys; however, there is a portion of evil youth, not necessarily poor, who are a real problem for society. A large number of them are thieves, common criminals, who enter and leave jail with ease. They know about the deficiencies of the penal systems and that is why they continue committing crimes; in other words, there is no law that can keep them in jail and keeping them in jail continues to be an economic problem for society and that morally does not solve anything; since in the prisons, there is not enough people who worries about a true social rehabilitation; on the contrary, they learn more ways to commit crimes and evade justice, due to corruption in some prisons, in the judicial and political systems.

A paradigm shift; It could be that if criminals are somehow punished by forcing them to belong to the army, this could help reduce common crime. This applies to corrupt civil servants and policemen and even if they are old, they can serve as a dishwasher in the military.

One option to recruit them is to find a way to sentence them to compulsory military service for at least 10 years, depending on the crimes committed, keeping in your file the reason for which they were recruited, if necessary, place a discreet location bracelet on them. For this and if possible, it will be necessary to establish some regulations or change some laws corresponding to these various crimes and also change the military laws to treat this type of recruits, to monitor their discipline or in case of desertion.

The main reason for this recruitment policy is not just to "punish" the common criminal; if not, to give him good technical training at a high level, in an area of his preference, in the last two or three years in the military service.

A condition may be that, if those recruits who were sentenced to serve in the army, do not satisfactorily comply with their technical training, which for them will be mandatory, they will not be able to be released at the end of their term; This program only applies to common criminals and not to criminals with high impact crimes. For the recruited volunteers, both women and men, their training will be voluntary, highly recommended.

The economic costs of all kinds, generated to society by common crime, could be greater than the extraordinary costs generated by events such as cyclones, earthquakes, nuclear accidents, etc.

TRAINING AREAS: each region of the country will need to define the areas most appropriate to its natural resources and industrial development.

Starting with the completion of their primary studies, or all their primary studies, those that require it, emphasizing such important topics as civics, human relations, another language, reading and mathematics, to then begin their development as technicians in: Agriculture, machine tools, mechanics, automotive, electricity, electronics, carpentry, construction, among many other trades. Without stopping to see the possibility that they carry out secondary studies and if possible, continue studying at a university.

The training of private soldiers is independent of the education and training of higher academic level, which is given in the military schools, an inherent achievement must be the development of a strong patriotism.

Existing technical schools can be used for training, rather than new facilities. In this way, these schools can be improved, increasing their space, capacity and equipment.

If the discipline in the army is to work as a team, in its final training phase, also train them to form cooperatives and partnerships, especially in agriculture and thus make themselves known to society before retiring from the army.

Complementary tasks, in addition to its tasks and military war training, the army could carry out complementary activities to obtain savings in its expenses. Those trained in construction will be able to handle the manufacture of bricks, blocks, etc. to self-provide for construction of new military facilities, repairs and remodeling. As well as, provide the civil government with the purpose of saving expenses, without generating unfair competition to private producers. In the same way, the other trades will be able to carry out all kinds of installations, furniture manufacturing, electrical installations and modifications to their installations, etc.

Other tasks and complementary training for soldiers who do not wish to receive training in any trade, are the support of the army in cases of contingency, such as floods, earthquakes, major fires, or other types of major accidents, with surveillance and direct support to the population. or wildfires with a fleet of planes large enough to put out a fire promptly. Sadly, there are thousands of fighter jets and quite a few for these events or community service. Just as it could contribute to the construction of military installations, it could contribute to the reconstruction of communities devastated by extraordinary events; if not $100 \%$, at least initially and that it is the people who finish the construction of 
their homes and those trained in plumbing, electricity, also do their part, if it is possible to integrate these policies into the training system.

New paradigms: The army can be part of the solution to reduce the number of people in the superfluous economic population and the negative, coupled with the training of the soldiers, some of these, already trained, could train the peasants; in trades such as mechanics, welders, carpenters, electricians, repair of power tools, etc. The more sophisticated a system is, the more vulnerable it becomes, so the advance in artificial intelligence must be balanced with the basics for the subsistence of human being. It is utopian that in the countryside there are people of all ages, with different levels of health and it could be sometimes with poor nutrition working to obtain food for themselves and those who live in the cities and also fighting against desertification in some places; when in the armies you have young people with all their physical abilities, training to "defend their country".

There may be more weapons than agricultural equipment and that more manhours are spent in armies than in agriculture in the world. The weapons are not charged to the soldier, but the agricultural equipment is charged to the farmer. What is clear is that military equipment is worth tens or hundreds of times more than agricultural equipment and has less useful life. From the point of view of Anthropoecology, that shows us that we are mentally ill.

An excellent example of negative consequences for refusing to change and sticking with the old paradigms is the Swiss watch industry. In 1967 they rejected the opportunity to continue dominating the watch market, for not having accepted the new technology in the way of measuring time, with quartz watches, invented by their own people; in Switzerland itself, as happens with other companies or nations by not accepting the new paradigms, sometimes necessary, not to evolve; if not, just to stay on the same level. [As shown in the video posted by: \#rompeparadigma new ideas,TikTok, @ma7heusskyway].

OBSERVATIONS: This is one more example of technological paradigm shifts. Leaving the old technological paradigms does not necessarily have to be bad; the bad thing is in the concentrated handling in all aspects, creating more technological illiterates.

We have an excess of gadgets and devices that induce children to violence from that early age and the implicit premise is fulfilled that if adults approve; then, it is valid.

Computers and automated systems will never be more intelligent than human beings, we have confused their capacity for speed, resolution and repetition in very narrow ranges, compared to the inconsistency of the human being.

It is in this aspect where the technocrats are forgetting nature itself, society and the problems that may arise from it due to these radical changes and contrary to natural laws. Balancing the temptations of technological advance with human well-being will not be easy, but it will be worth it especially for those sectors geographically far from technological advance; but what if it contaminates them.

COUNTRIES WITHOUT ARMY: Until 2019 AD. There were 31 countries that did not have an Army; of those countries, only Costa Rica and Panama are autonomous countries. Costa Rica being one of those 31 countries, which does not have a history as a tax haven. And being a small country, the benefits of not having an army may seem insignificant.

COSTA RICA: "How much the Costa Rican economy has gained thanks to its decision to abolish the army 70 years ago? For decades, supporters of eliminating the armed forces of the countries have argued for this moral, philosophical, political and also economic reasons, considering that it is a ruinous business. The Development Observatory of the University of Costa Rica, which assures that the decision to get rid of the military forces meant an increase of almost one percentage point in the average annual growth of the Gross Domestic Product (GDP) per capita between 1950 and 2010. Earnings additional; public investment in education in Costa Rica reached 35\% of public spending in 1969, as well as in health and infrastructure, Costa Rica hardly suffered political and civil violence since 1951." [December 1, 2018, https://www.bbc.com / world / news-latin-america-46407922].

OBSERVATIONS: Costa Rica is considered one of the most stable countries in the region, in all its aspects, apparently citizens feel responsible for the welfare of their society.

"THE 31 COUNTRIES WITHOUT AN ARMY": "And almost all of them are tax havens. There are nations that not only receive capital in the wild as off-shore centers and their normative benevolence towards fiscally harmful practices. Most of them, in addition, save the military bill. They have no armed forces. Although their national security is guaranteed by great superpowers." [MADRID 04/11/2019 08:29, https://www.publico.es/economia/son-31-paises-noejercito-son-paraisos-fiscales.html].

"DEFINITION OF THE PLAN-DN-III-E": “Military operational instrument that establishes the general guidelines for the Mexican Army and Air Force agencies, to carry out relief activities to the population affected by disasters of natural or human origin, optimizing the use of human and material resources for their timely, effective and efficient care, also supporting the preservation of their property and environment.

" [https://www.gob.mx/sedena/acciones-y-programas/que-es-el-plan-dn-iii-e].

OBSERVATIONS: Plan-DN-III-E is an example of an army with a direct support plan for the civilian population. 


\section{CONCLUSIONS}

1. From the point of view of Anthropoecology, these aspects will minimize the superfluity of the existence of the armies and could at least reduce the crime sometimes supported by the police themselves in the streets, which directly affects the people.

2. This will make a truly and socially responsible army, which at the end of its service in the army, a good person will be delivered to society.

3. The final result will be that after fulfilling his years of commitment in the army, a citizen will come out trained for work, disciplined and obedient to civic norms, grateful to his army and his country, committed to his homeland and his society, reinforcing their patriotism. Having an army of patriots and not of hired mercenaries.

4. In this way, a criminal is not deprived of his liberty, he is only assigned a task to compensate for the damage he has caused and to prevent him from doing more harm to society.

5. Although there are only a few countries without an army, Costa Rica is an example of how you can live better without an army. This shows that the military is a superfluous and costly activity.

6. With these programs, nationalism should be reinforced in all areas of the country and, in turn, achieve selfsufficiency of each of the regions, especially in agriculture, with medium to small machinery, with the capacity to support the cities with food.

7. It seems that in the technological race and in artificial intelligence, there is no other way but innovation; However, the country that forgets the basics of life, will perish for its own people, production must be dispersed, especially agriculture, both socially and geographically.

8. Do not forget that a truly unhappy and impoverished society is the worst burden for the stability and true progress of a group or country.

\section{REFERENCES}

1. https://www.gob.mx/sedena/acciones-y-programas/que-es-el-plan-dn-iii-e

2. https://www.publico.es/economia/son-31-paises-no-ejercito-son-paraisosfiscales.html, MADRID 04/11/2019 $08: 29$

3. https://www.bbc.com/mundo/noticias-america-latina-46407922, December 1, 2018

4. Posted by: \#rompeparadigma new ideas, Tik Tok, @ ma7heusskyway

5. The Kingmaker, Phillipa Gregory, Posted by Simon \& Schuster, 2012

6. https://www.newsmadretierra.com/ubuntu-una-filosofia-de-vida/
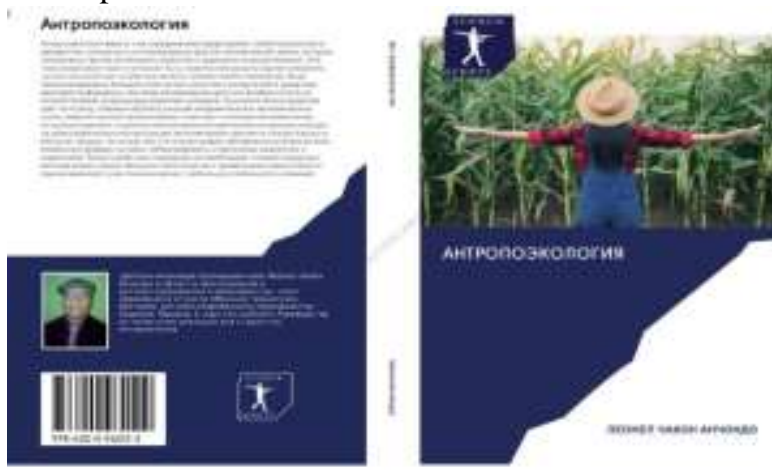

978-620-2-12192-7 Spanish

978-620-0-96012-2 Russian

978-620-0-96011-5 German

978-620-0-96019-1 Dutch

978-613-9-85828-6 English

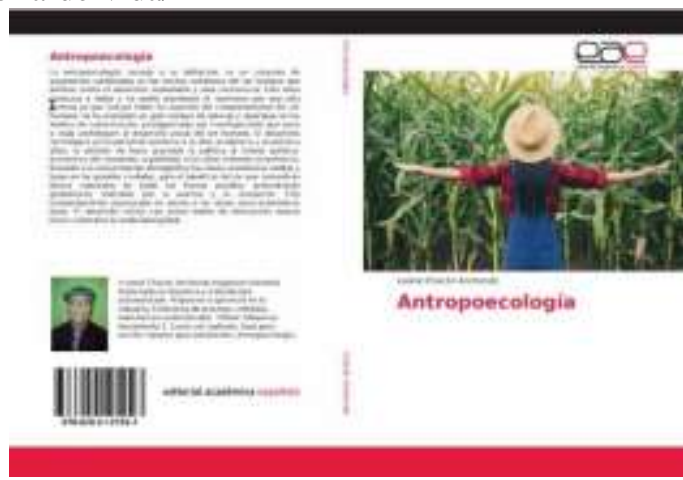

978-620-0-96013-9 French

978-620-0-96017-7 Italian

978-620-0-96014-6 Portuguese 978-620-0-96021-4 Polish 